\title{
HyFlex Course Delivery: Addressing the Change in Course Modality Brought on by the Pandemic
}

\author{
Tonia J. Wilson \\ Melina Alexander \\ Weber State University, USA
}

\begin{abstract}
Teacher preparation programs need quality training courses that offer flexible, interactive alternatives to isolating online courses and classroom-based programs that limit students to a specific place and time. The HyFlex course design provides a solution by combining internet video instruction (such as Zoom), regular online learning, and face-to-face classroom experiences into one course where students can choose the method that best meets their individual learning needs and even alternate between methods throughout the course session. HyFlex aligns with learner centered instruction and offers a unique opportunity for educators to receive quality licensure courses. This article explores existing literature on the HyFlex course delivery method and discusses a case study done to examine student outcomes resulting from its use in a post-baccalaureate special education teacher licensure program.
\end{abstract}

Keywords: HyFlex, rural special educators, online teaching, course delivery, hybrid course

\section{Introduction}

The twenty first century has brought forth many changes to higher education leading to a re-evaluation of course delivery options. Universities across the globe are seeing an increase in student numbers, including higher rates of female students (ICEF Monitor, 2018). This is particularly true for teacher preparation programs. Globally, female primary school teachers outnumber males (Roser \& Ortiz-Ospina, 2013). In areas such as the US and the UK these increases include more non-traditional students, those over the age of 21 (Hanson, 2021; HESA, 2021). These demographic changes mean that, in order to be successful, students desire an increased flexibility in course structure. To meet student need, many US universities have felt compelled to increase the number of asynchronous online course offerings (Lederman, 2018).

Compounding this issue, over the past two years, institutions of higher education have had to face the challenges unique to the ongoing the COVID-19 pandemic. Students who had previously taken classes on campus were no longer safe meeting face-to-face (FTF). Many universities instituted rapid change in course delivery to asynchronous online and synchronous virtual modalities in order to keep students healthy and safe. 
Unfortunately, for faculty and students, this quick movement to online and virtual formats caused a large amount of stress (Flaherty, 2020; Ghazi-Saidi et al., 2020). Faculty felt pressure to create and administer courses in formats for which they were unfamiliar, and students were required to take courses in modalities they did not choose, some of which were poorly created due to faculty naiveté in course design.

Although some universities are returning to the pre-pandemic modes of instruction, most are maintaining a higher level of alternative course modalities including both virtual synchronous classes and online asynchronous courses. These circumstances create an impetus to design courses that can be delivered in a variety of modalities.

\section{Literature Review}

\section{Online and Distance Learning}

Changes in higher education student demographics, and the upheaval of the pandemic has made it clear that new modes of course delivery are necessary and here to stay. Course delivery formats usually fall into two distinct temporal categories; synchronous, where all students receive instruction at the same time, and asynchronous, where students can access instruction at a time that is convenient to them (Rehman \& Fatima, 2021). From these two constructs a variety of modality offerings have emerged. Instructors can claim to offer courses that use blended learning, flexible learning or a flipped classroom model, they may be labeled hybrid or multimodal, leading to confusion on what these terms mean (Perry \& Pilati, 2011). However, the name used usually tries to indicate how the instructor provides learning opportunities, whether it is synchronous or asynchronous, or occurs live or through technology. Consequently, there is a plethora of contradictory research indicating which modalities are more advantageous for students (Reeves \& Lin, 2021). Most modalities offer some benefit for some students.

This paired with the changing student demographics indicate that most courses should be offered using a variety of delivery modes. This creates a challenge for higher education programs, particularly those in teacher preparation where courses are determined based on faculty availability and student numbers. Offering multiple sections of one course, each addressing a different delivery mode, proves an impossible challenge. One way to address this challenge is through utilizing blended learning.

Blended Learning. Blended learning consists of combining instructional modalities and methods into one class (Graham, 2006). Blended learning is also known as hybrid instruction where the instructor chooses which material to teach FTF and which to provide 
online. The concept of teaching simultaneously in more than one delivery modality is not new, although recent events have caused a resurgence of interest in the topic (McMurtrie, 2020). The need to provide options for students who are unable to attend in-person courses has long driven innovation in course delivery.

Distance education in Australia is a noteworthy example. Due to Australia's widespread population, addressing educational needs in rural areas has been, and continues to be of primary concern to state and federal governments (Stacey \& Vissar, 2005). Indeed, the first blended course delivery method may have its roots in the "School of Air" launched in 1951. The "School of Air" provided classes to in the Outback via two-way radio. This was done in conjunction with correspondence materials delivered by mail. Later, content experts in fields such as foreign language and physics who were not available in rural communities would gather around speaker phones and use dial-up modems to link students using classroom computers. Australia continues to meet the needs of their rural populations with the most upto-date technologies combined in innovative ways (Qayyum, \& Zawacki-Richter, 2018).

Australia is not alone in its use of blended learning methods; blended delivery models have risen in popularity over the last two decades. For example, Peirce College, a private institution in Philadelphia catering to adult students, has made all of their courses available in a blended format with positive results (Fabris, 2015). The Université de Sherbrooke in Montreal adopted what they called the "blended synchronous course delivery mode" in 2006 and are still using it today for their graduate level Master Teacher Program (Lakhal et al., 2017). Their structure requires local students to attend in person but gives distance students the option to attend synchronously via internet video. Both modalities are supplemented by online material and assessments. Other institutions worldwide are using variations of the blended synchronous delivery method to enhance student choice in learning (Eliveria et al., 2019).

There is research to support the use of a blended model. Blended learning courses have been shown to increase student learning, provide a better sense of classroom community and are preferred by students over FTF instruction alone (Bower, et al., 2015; Irvine et al., 2013; Lakhal et al., 2017). It is interesting to note the majority of studies found in the extant body of research examine outcomes for students enrolled in graduate-level programs (Hall \& Villareal, 2015; Lakhal et al., 2017). However, for teacher preparation, the authors have promoted using and shown the efficacy of using blended learning in teacher preparation at all levels, including undergraduate level teacher preparation (Duhaney, 2012; Kimmelmann \& Lang, 2019; Parra et al., 2019; Pilgrim et al., 2017).

Teacher Preparation and Blended Learning. Blended learning is increasingly being 
adopted as a means to prepare teachers, and is seen as a way to integrate instructional technologies' use and proficiency (Duhaney, 2012). According to Duhaney, blended learning classes in teacher preparation must include orientation to the model, use information communication technologies, and be integrated across the entirety of the program. If done well, teachers will adopt the use of technologies that increase opportunities for student learning and engagement. Studies have indicated the effectiveness of the use of blended learning in teacher preparation programs. Blended learning is shown to be effective for virtual internships (Theelen et al., 2020), for teaching explicit instruction and listening techniques (Yoon \& Lee, 2012), and for building community during student teaching (Ateş Çobanoğlu, 2018). Student satisfaction with blended classes has been noted for graduate students (Wong et al., 2021) and for in-service teachers as well (Mouzakis, 2008).

Although blended learning has been shown to be efficacious, it is not without its detractors. Oliver and Trigwell (2005) note that blended learning often ignores the position of the learner. They state that the name does not adequately describe what is taking place in the learning environment which is that courses often provide the same instructional methods in both online and a FTF modalities. Pilgrim et al. (2017) also outline the barriers to student success in blended learning. They say that students may grapple with course clarity and expectations and may struggle with issues inherent in online education for those that are not adequately prepared for the online structure. This can include feeling a lack of support, isolation, and feeling unfamiliar with the technology requirements.

In addition to these concerns, blended learning does not allow for student choice in instructional modality. It combines modalities which can inhibit access to students with other life demands. A method for combining the benefits of blended learning while addressing student barriers and course offering limitations is the hybrid flexible or HyFlex Model.

HyFlex Course Design. Utilizing a flexible hybrid or multimodal course design that allows students to choose their learning modality helps address challenges inherent in blended learning. The hallmark of these flexible hybrid course designs is the HyFlex model (Beatty, 2007). HyFlex incorporates synchronous, FTF instruction, live internet video instruction and asynchronous online course delivery all within the same course.

Unlike other hybrid or multimodal courses where all learning modalities are blended according to the instructor or designer's preference, the HyFlex model allows the student to choose which learning modality best meets their needs. Using principles of learner-centered instruction in course design for all modalities, the HyFlex course model claims to maintain the quality and rigor of a traditional FTF program (Beatty, 2007). 
HyFlex modalities may include: (a) synchronous, FTF, (b) synchronous, virtual, (for example, Google Meet, Zoom, or Skype) and (c) asynchronous online (Lakhal et al., 2017, Beatty, 2007). Each learning structure is available to all students for any given class meeting (see Figure 1).

\section{Figure 1}

\section{HyFlex Course Structure}

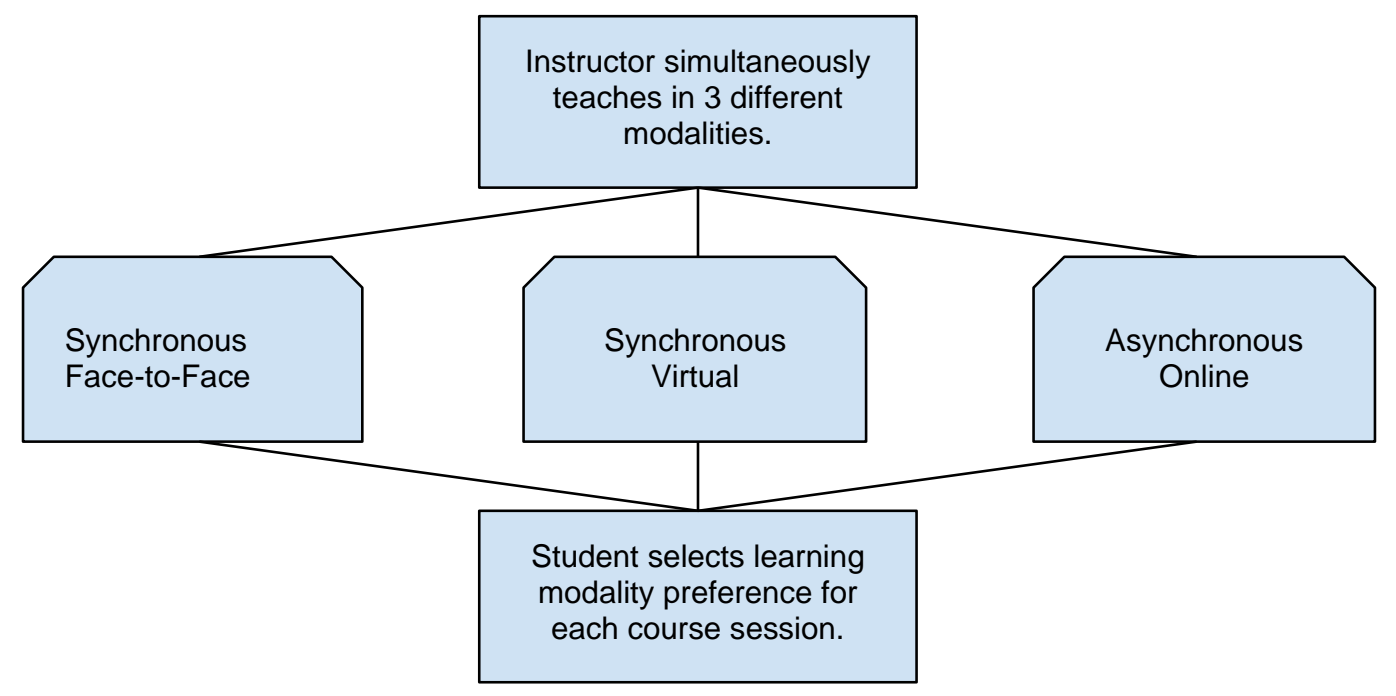

By including multiple modalities in one class, including traditional FTF and distance options, the HyFlex model addresses many challenges faced by today's students. This is especially beneficial in teacher preparation programs where some students work in primary and secondary schools. When students have unexpected work demands during a given class session, such as parent meetings and after school activities, they can choose the asynchronous option without missing any vital course material. Additional benefits of the HyFlex model are outlined in Table 1.

The HyFlex model has been shown to be preferred over other course modalities by students (Beatty, 2007). In addition, the HyFlex model promotes higher levels of student participation over traditional FTF courses, and higher levels of student satisfaction in their learning experience (Malczyk, 2019). Samuel et al. (2019) found HyFlex increased both enrollment and retention. Other studies demonstrate that blended models such as HyFlex support faculty in their efforts to help students achieve desired learning outcomes (Bower et al., 2015; Fabris, 2015; Kyei-Blankson \& Godwyll, 2014). Additionally, instructors are afforded the same flexibility their students enjoy by having all three modalities to draw upon as needed. The rapid movement to asynchronous online and synchronous virtual formats 
precipitated by the pandemic was an easier transition for those whose courses already had online and virtual options embedded in their design. While there is research to support the use of the HyFlex model, the authors could find no information about the inclusion of this design in teacher preparation programs.

\section{Table 1}

Benefits of HyFlex Courses

\begin{tabular}{lll}
\hline \multicolumn{2}{c}{ Financial Benefits } & \multicolumn{1}{c}{ Practical Benefits } \\
\hline University or & $\begin{array}{l}\text { Less classroom space needed. } \\
\text { College }\end{array}$ & $\begin{array}{l}\text { More students. Greater reach into } \\
\text { rural communities. }\end{array}$ \\
Rural School & No travel expenses to bring quality & Ability to combine many single \\
Districts & instruction to educators. & $\begin{array}{l}\text { learners from rural areas into one } \\
\text { interactive course can provide }\end{array}$ \\
& & higher quality training. \\
Individual & No travel expenses. Access to a & No need to schedule work around \\
Students & wider variety of courses. Quality & course offerings. Flexible \\
& interaction with classmates and & attendance options exist throughout \\
instructors.
\end{tabular}

\section{Current Study}

The case study under examination involves a 15 -week post-baccalaureate mathematics methods course included as part of an alternative route to teacher licensure program at a midsize state university in the Western US. This course was offered using the HyFlex modality option. Students taking this course were all on emergency licensure and teaching K-12 special education and had been teaching special education for 2 years or less.

\section{Participants}

A total of 38 students were enrolled in this course. Thirty-three of the 38 students passed the course at an acceptable rate by the conclusion of the course, an additional three students finished and passed the course within a month of the course ending. The remaining two students were required to retake the course. Twelve participants agreed to be interviewed and permit their grade and attendance data to be included in this study. Of the 12 students, survey data indicated five chose to attend only synchronously, two others only asynchronously and the 
other five opted to use both asynchronous and synchronous options throughout the course. To honor case study methodology's focus which allows the researcher to "understand behavioral conditions through the [participant's] perspective." (Zainal, 2007, p. 1) only one participant from each of these three attendance categories was randomly selected for an interview.

To facilitate the online portion of the course an online learning management system (LMS) named Canvas, was used. The platform allowed for the creation of grouped content or modules that all students could access at any time during the semester. For example, a module could include an online discussion board, a course reading, an assignment based on that reading and an online quiz. Students would also submit their assignments, email other students and their instructor, and view video content on this platform.

\section{Setting Up the HyFlex Course}

The class curriculum was created using the backward design method (Wiggins \& McTighe, 2005), starting with the online layout. Backward design involves three stages: (a) identify learning objectives; (b) determine outcome evidence or assessments and (c) plan learning content and instruction. Using this process, learning objectives, assessments, classroom activities and lectures were fully established, prior to structuring the online version of the course.

Next, thirteen weekly content modules were created in the LMS. Two additional weeks were also included where students implemented and reflected upon a math instruction unit taught in their teaching placements. Each module contained information regarding the predetermined lesson topic for the week. Topics included both instructional methods for mathematic content areas and strategy instruction approaching math tasks. Each content module was divided into three subsections; activate prior knowledge (Activate), gather information on the topic (Gather), and apply what was learned from the gather section (Apply). These sections were chosen based on constructivist theories of learning.

When accessing the Activate section of the module, all students, regardless of modality choice, were required to contribute to an online discussion prior to accessing additional information either asynchronously online, or attending the synchronous session FTF or virtually. The asynchronous discussions were conducted by posting a prompt on the learning management system discussion board where students could then enter their responses and reply to other students' comments. Activate questions varied across instructional content but included probing questions, such as, "Thinking back to your experience as a student in the K12 classroom, how were you taught about place value?"

After completing the Activate discussions students either accessed information in the 
Gather section of the module, or obtained content by attending a synchronous class section. For example, students attending the section asynchronously may access reading materials and videos related to the topic. Those attending a synchronous session would be provided access to activities and materials linked to the same topic.

Finally, for the Apply section of the module students were asked to complete activities related to the topic. For example, in the addition module, students were required to find a lesson plan online and provide adaptations that allowed access to the lesson content for students with disabilities. These activities were completed independently by students attending either the asynchronous or synchronous sessions. All assignments were submitted using the course LMS.

In the course examined here, all students were required to attend the first session synchronously where the HyFlex course delivery model was described to them. They were told they could attend each week in any modality they chose. It was emphasized that there was no instructor preference to their modality choice and there was no need to notify the instructor of their choice for any given week. Additionally, it was made clear grading outcomes would not be reflective of how they decided to attend each session.

\section{Study Design}

An exploratory case study was conducted to determine the student participation in and perceptions of the HyFlex model of course delivery (Creswell \& Creswell, 2017; Zainal, 2007). These outcomes were examined through class attendance analysis, student grades, and student interviews. Statistical analysis of data was performed using standard linear regressions calculated in Excel. The following research questions guided the analysis:

1. Does allowing students to choose between asynchronous and synchronous learning modalities within a single course affect student learning as measured by grade percentage?

2. What are special educator perceptions and preferences regarding the HyFlex course delivery method in a teacher licensure course according to course delivery method choice?

\section{Procedures}

To address research question one, course attendance data were gathered to determine if students participated completely synchronously (FTF or via internet video), asynchronously (online only) or used a mixed selection of both methods for each of the 13 class sessions. A standard regression analysis used percentage of asynchronous courses attended to predict student performance. Percentage of asynchronous sessions was the independent variable and overall course percentage was the dependent variable. Course percentage was calculated by 
averaging the scores of three key course areas: (a) activate discussions, (b) assignments and (c) the final unit lesson plan.

Examination of research question two was conducted through student interviews. As a qualitative element of this case study, the results of the interviews were not intended to generalize to other groups; rather, we hoped to gain insight into the particular student needs existing within the context of a teacher preparation course (Creswell \& Creswell, 2017). First, students were asked if they would agree to an interview on their perceptions and preferences with respect to the HyFlex course delivery method. Twelve students agreed to the interviews.

Next, the authors examined the course taking practices of those students. It was determined that three categories of course modality choice were represented among the possible interviewees: (a) synchronous only, (b) asynchronous only and (c) mixed. Next, each participant was placed in one of these three categories according to their attendance record. Finally, one student from each category was selected at random for an interview. Participants 1,5 , and 11 were interviewed using the following questions:

1. Which delivery option did you choose?

2. Did you prefer a delivery option?

3. How much time did you spend on course content for each modality?

4. Could you give me some pros and cons of each modality?

5. What could we do to improve the course delivery?

6. Do you have anything else we should know?

\section{Findings}

\section{Research Question 1}

Participant attendance and grade data are included in Tables 2 and 3 respectively. All participants attended all sessions and twelve out of the thirteen participants received passing grades.

\section{Table 2}

Attendance Data

\begin{tabular}{llll}
\hline Participant & $\begin{array}{l}\text { Sessions } \\
\text { Synchronous }\end{array}$ & $\begin{array}{l}\text { Sessions } \\
\text { Asynchronous }\end{array}$ & $\begin{array}{l}\text { Percentage of } \\
\text { Asynchronous }\end{array}$ \\
\hline 1 & 12 & 1 & $8 \%$ \\
2 & 9 & 4 & $31 \%$ \\
3 & 0 & 13 & $100 \%$ \\
4 & 0 & 13 & $100 \%$
\end{tabular}




\begin{tabular}{llll}
5 & 13 & 0 & $0 \%$ \\
6 & 7 & 6 & $46 \%$ \\
7 & 11 & 2 & $15 \%$ \\
8 & 13 & 0 & $0 \%$ \\
9 & 0 & 13 & $100 \%$ \\
10 & 0 & 13 & $100 \%$ \\
11 & 0 & 13 & $100 \%$ \\
12 & 2 & 11 & $85 \%$ \\
\hline
\end{tabular}

Table 3

Participant Grade Data

\begin{tabular}{lllll}
\hline Participant & $\begin{array}{l}\text { Activate } \\
\text { Discussions }\end{array}$ & Assignments & Final Unit Plan & $\begin{array}{l}\text { Grade } \\
\text { Percentaoe }\end{array}$ \\
\hline 1 & 100 & 100 & 96 & $99 \%(\mathrm{~A})$ \\
2 & 100 & 97 & 55 & $84 \%$ (B) \\
3 & 100 & 47 & 0 & $49 \%$ (F) \\
4 & 100 & 97 & 100 & $99 \%$ (A) \\
5 & 92 & 95 & 89 & $92 \%$ (A-) \\
6 & 100 & 90 & 96 & $95 \%$ (A) \\
7 & 100 & 100 & 100 & $100 \%$ (A) \\
8 & 100 & 87 & 90 & $92 \%$ (A-) \\
9 & 100 & 100 & 100 & $100 \%$ (A) \\
10 & 100 & 92 & 100 & $97 \%$ (A) \\
11 & 92 & 90 & 100 & $94 \%$ (A) \\
12 & 100 & 95 & 86 & $94 \%$ (A) \\
\hline
\end{tabular}

Note. Grade percentage was determined by averaging scores from the Activate Discussions, Assignments and Final Unit Plan.

Model summary statistics are found in Table 4. A simple linear regression was calculated to predict student grade percentage based on percentage of asynchronous classes attended. A non-significant regression equation was found $F(1,10)=0.41 . p>0.54$, with an $R^{2}$ of 0.04 . Participants predicted grade is equal to $0.95-0.06$ (asynchronous classes) percent when asynchronous classes attended is measured by percentage (see Tables $5 \& 6$ ). Grade percentage decreased 0.06 percent for each percent increase of asynchronous classes taken.

\section{Table 4}

Descriptive Statistics 


\begin{tabular}{lll}
\hline Variables & $M$ & $S D$ \\
\hline Grade Percentage & 91.28 & 14.06 \\
Synchronous & 5.58 & 5.74 \\
Asynchronous & 7.42 & 5.74 \\
\hline
\end{tabular}

Table 5

ANOVA

\begin{tabular}{llllll}
\hline Model & df & SS & $M$ & F & Sig. \\
\hline Regression & 2 & 84.76 & 42.38 & 0.41 & 0.068 \\
Residual & 10 & 2089.87 & 208.99 & & \\
Total & 12 & 2174.63 & & & \\
\hline
\end{tabular}

\section{Table 6}

Coefficient Estimates of the Model

\begin{tabular}{lcccccc}
\hline Model & \multicolumn{2}{c}{ Unstandardized } & & Standardized & \multirow{2}{*}{ Sig. } \\
\cline { 2 - 3 } & Coefficients & St. Error & & Beta & & \\
\hline Constant & 94.86 & 7.01 & & & 13.54 & 0 \\
Synchronous & 0 & 0 & & 0 & 65535 & - \\
Asynchronous & -0.48 & 0.76 & & -0.20 & -0.64 & - \\
\hline
\end{tabular}

Student selected course modality does not appear to impact student learning outcomes. Although there was a slight negative effect from attending more asynchronous courses, it was extremely small (see Figure 2). Students attending synchronously, asynchronously and a combination of both achieved similar success. Importantly, due to the small sample size and limited number of students taking synchronous classes only, results are not generalizable beyond this course. Additionally, the range of scores on the outcome variable was limited, which may be masking differences.

\section{Figure 2}

Student Grade Percentage by Percentage of Asynchronous Courses 


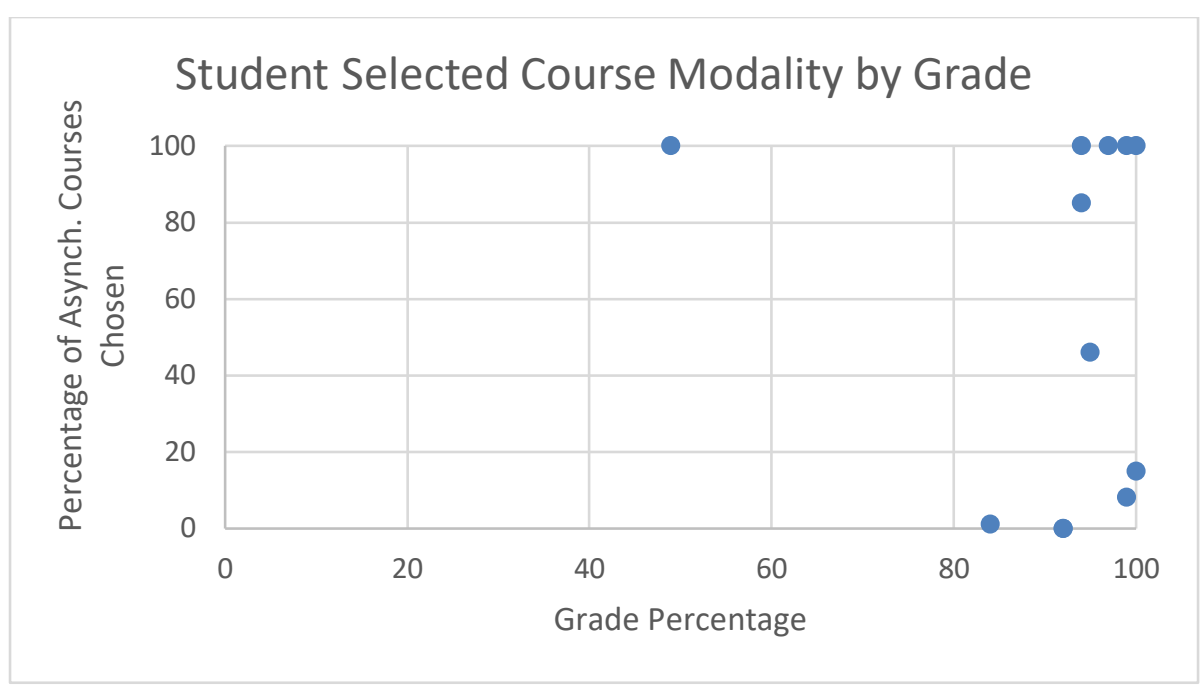

Note. The scatter plot shows that student grades were similar regardless of the number of courses they chose to attend synchronously or asynchronously.

\section{Research Question 2}

Interview Results. Interview responses regarding the HyFlex model were overall positive and quite informative. Student answers to each interview question are included below. Note: in the comments below, "virtual" refers to synchronous class attendance through Zoom and "online" refers to asynchronous attendance facilitated through the Canvas learning management system.

\section{Question 1: Which delivery method did you choose?}

P1: I attended both virtually and online. I was planning on coming to class each time, but we had spring break at the same time as one of the classes and my family decided to take a vacation. I also had an IEP that ran late one night...I guess there were a couple of nights I just couldn't make it.

P5: Virtual, I went to a distance site.

P11: Online

\section{Question 2: Did you have a preference for a delivery option?}

P1: Oh yes, I really liked the available help for the assignments (during the synchronous class). I was never a math person and I really needed the peer support.

P5: Yes, I like having other students around so I can talk to them later if I have questions. I don't really learn well online.

P11: Not usually but I already teach math, so I couldn't see why I needed to attend (FTF) class.

\section{Question 3: How much time did you spend on course content for this modality?}

P1: I am not sure. I know I only spent class time on the nights I attended. For the online 
sessions I think it took me about three hours to read and review the materials in the module, then I had to do the assignment after that, so longer than the nights I attended, I guess.

P5: I came to class, so the two and $1 / 2$ hours each week, then I did look at some of the online materials for the math areas I am teaching. Do you want to know the time I spent reading the text as well? So, I guess maybe an additional 20 hours. Then there was the math unit, so I accessed the planning module as well, so maybe five more hours?

P11: About five hours a week

\section{Question 4: Could you give me some pros and cons of each modality?}

P1: Well, I liked that I could have the option to miss class with the online materials, but I wasn't sure about some of the content. I got really confused on the lesson planning assignment. The standard that it was linked to didn't make sense to me. I guess I liked the virtual classes, but one night my internet kept freezing so it was hard to stay focused. I also didn't like how it took forever for the sites to log in.

P5: As I said, I really like attending with my peers, I also really like that the materials for the online group are available on Canvas so I can look at them. The course recordings are also there, but to be honest I didn't access them. Cons? hmmm, maybe that class started late every week?

P11: If you are asking about the online format not really, it was okay. I mean you checked to see if we knew what we learned each week, which is good. I didn't really see the purpose of the activate activities, but I guess if you didn't already teach math it might make sense.

\section{Question 5: What could we do to improve the course delivery?}

P1: It would have helped to take a math class first, it had been years (slight laugh). But you mean the way we access the course, right? Okay, I guess make sure you let people know they need a strong internet connection to access the course virtually, Also I think you should do away with the distance sites, this took way too much time. I am not sure really on the online delivery, maybe more clarity in the assignment instructions? But only some of them, you know the ones that required higher math content knowledge. P5: Start class later.

P11: I would include more rigorous assignments outside the module assignments. I already had unit plans so that assignment was a piece of cake. I would include an assignment to see if other students know their math, my assumption would be no.

\section{Question 6: Do you have anything else we should know?}


P1: Not really.

P5: I guess just that even though I didn't attend online it was nice to know that it was there if I needed it.

P11: Yes, I would take off the requirement of reading all the material. If we already know math some of the readings are too basic.

Based on the comments of interviewees, it is clear that each student's learning needs are highly specific. As indicated, giving students modality choice created flexibility to attend sudden meetings or even go on vacation without missing class. It is also interesting to note that two students appreciated the synchronous interaction of the instructor and peers while the other student did mind its absence. Although it's difficult to say, if both options had not been available, student learning may have been affected negatively for any one of them. Finally, comments of participant 1 on Question 4 emphasize the importance of thoughtful, welldesigned instruction when building a HyFlex course.

\section{Discussion}

The current case study supports earlier, positive research outcomes associated with providing student modality choice using the HyFlex course delivery method, including enhanced learning quality and higher student satisfaction (Bower et al., 2015; Fabris, 2015; Kyei-Blankson \& Godwyll, 2014; Malczyk, 2019). Adding to the extant literature, we found this method to be useful for special education teacher training, a population which has not been previously examined. Because educators in alternative routes to licensure settings may feel overwhelmed by job responsibilities inherent in the first few years of teaching, providing choice in delivery modality proved to be beneficial for students. Overall, participants in this study performed remarkably well, regardless of learning modality choice, shining a light on the HyFlex course delivery model as a viable means of meeting these goals. The authors agree that HyFlex can improve training opportunities in teacher preparation by offering greater flexibility for both students and providers (Beatty, 2007).

\section{Limitations}

There were limitations to the research in this case study. As with all case studies, it only provides a snapshot of the research outcomes in question. This study of the HyFlex model took place in a single post graduate teacher licensure course with few participants making results difficult to apply to other course types and institutions. Future studies could replicate these 
procedures using a larger population of students, possibly combining results from a complete teacher preparation program with multiple HyFlex courses or using longitudinal data gleaned from repeated courses. Finally, in order to truly understand students' experiences, more interviews are necessary.

\section{Conclusion}

As the student demographics of higher education and teacher education continue to change, the struggle to accommodate diverse learners will persist. The HyFlex teaching method provides unique access to quality training courses that can support learning. Learners that cannot travel can still attend interactive, flexible courses that are more personal than online only courses. In accordance with best practices of learner centered instruction, students benefit from flexibility and choice in how, where and when they learn (Cornelius-White \& Harbaugh, 2009). This model provides options for various synchronous and asynchronous course modalities, and, as evidenced here, the authors have experienced high student satisfaction and learning success when deploying it in teacher training.

The HyFlex model also provides benefits to institutions striving to serve diverse learners by combining modality preferences into existing classes instead of teaching additional sections. However, there are reasons to continue an exploration of best teaching practices for this course format to better understand it's connection to learning outcomes as well as practices to enhance student satisfaction.

\section{References}

Ateş Çobanoğlu, A. (2018). Student teachers' satisfaction for blended learning via Edmodo learning management system. Behaviour \& Information Technology, 37(2), 133-144.

Beatty, B. J. (2007). Hybrid classes with flexible participation options-If you build it, how will they come? In M. Simonson (Ed.), Selected research and develop papers presented at the 2007 Annual Convention of the Association for Educational Communications and Technology. (pp. 15-24). AECT. http://citeseerx.ist.psu.edu/viewdoc/download? doi $=10.1 .1 .903 .8934 \&$ rep $=$ rep1 \& type $=$ pdf $\#$ page $=24$

Bower, M., Dalgarno, B., Kennedy, G. E., Kenney, J., \& Lee, M. J. (2015). Design and implementation factors in blended synchronous learning environments: Outcomes from a cross-case analysis. Computers \& Education, 86, 1-17. https://doi.org/10.1016/j.compedu.2015.03.006

Cornelius-White, J. H. D., \& Harbaugh, A. P. (2009). Learner-centered instructions: Building 
relationships for student success ( $1^{\text {st }}$ ed.). SAGE Publications, Inc.

Creswell, J. W., \& Creswell, J. D. (2017). Research design: Qualitative, quantitative, and mixed methods approaches. Sage publications.

Duhaney, D. C. (2012). Blended learning and teacher preparation programs. International Journal of Instructional Media, 39(3).

Eliveria, A., Serami, L., Famorca, L. P., \& Cruz, J. D. (2019). Investigating students' engagement in a hybrid learning environment. IOP Conference Series: Materials Science and Engineering. https://doi.org/10.1088/1757-899X/482/1/012011

Fabris, C. (2015, March 24). Online or in-person? One college lets students switch back and forth. The Chronicle of Higher Education https://www.chronicle.com/blogs/wiredcampus/ online-or-in-person-one-college-letsstudents-switch-back-and-forth/56265

Flaherty, C. (Nov. 2020). Faculty pandemic stress is now chronic. Inside Higher Ed. Retrieved from https://www.insidehighered.com/news/2020/11/19/faculty-pandemic-stress-nowchronic

Ghazi-Saidi, L., Criffield, A., Kracl, C. L., McKelvey, M., Obasi, S. N., \& Vu, P. (2020). Moving from face-to-face to remote instruction in a higher education institution during a pandemic: Multiple case studies. International Journal of Technology in Education and Science, 4(4), 370-383.

Graham, C. R. (2006). Blended learning systems. In C.J. Bonk, C.R. Graham, \& J. Cross, (Eds.), The handbook of blended learning: Global perspectives, local designs, (pp. 321), Wiley.

Hall S., \& Villareal, D. (2015) The hybrid advantage: Graduate student perspectives of hybrid education courses. International Journal of Teaching and Learning in Higher Education, 27(1), 69-80.

Hanson, M. (2021). College enrollment \& student demographic statistics. Education Data Initiative. https://educationdata.org/college-enrollment-statistics

HESA. (2020). Higher Education Student Data. https://www.hesa.ac.uk/data-andanalysis/students/whos-in-he\#characteristics

Irvine, V., Code, J., \& Richards, L. (2013). Realigning higher education for the 21 st-century learner through multi-access learning. Journal of Online Learning and Teaching, 9(2), 172-186.

http://www.academia.edu/download/52598297/Realigning_higher_education_for_mul ti-ac20170412-29773-x03kez.pdf 
Kyei-Blankson, L. \& Godwyll, F. (2010). An Examination of Learning Outcomes in Hyflex Learning Environments. In J. Sanchez \& K. Zhang (Eds.), Proceedings of E-Learn 2010--World Conference on E-Learning in Corporate, Government, Healthcare, and Higher Education (pp. 532-535). Association for the Advancement of Computing in Education (AACE). LearnTechLive. https://www.learntechlib.org/ primary/p/35598/.

Kimmelmann, N., \& Lang, J. (2019). Linkage within teacher education: cooperative learning of teachers and student teachers. European Journal of Teacher Education, 42(1), 5264.

Lederman, D. (2018). Who is studying online (and where). Inside Higher Ed, 5.

Lakhal, S., Bateman, D., \& Bédard, J. (2017). Blended synchronous delivery mode in graduate programs: A literature review and its implementation in the master teacher program. Collected Essays on Learning and Teaching, 10, 47-60.

Malczyk, B. (2019) Introducing social work to hyflex blended learning: A student-centered approach. Journal of Teaching in Social Work, 39(4-5), 414-428. DOI:10.1080/08841233.2019.1652226

McMurtrie, B. (2020). Are colleges ready for a different kind of teaching this fall? The Chronicle of Higher Education. https://www.chronicle.com/article/Are-CollegesReady-for-a/248710

ICEF Monitor (2018) Study Projects Dramatic Growth for Global Higher Education through 2040, https://monitor.icef.com/2018/10/study-projects-dramatic-growth-globalhigher-education-2040/

Mouzakis, C. (2008). Teachers' perceptions of the effectiveness of a blended learning approach for ICT teacher training. Journal of Technology and Teacher Education, 16(4), 461482.

Oliver, M., \& Trigwell, K. (2005). Can 'blended learning' be redeemed?. E-learning and Digital Media, 2(1), 17-26.

Parra, J., Raynor, C., Osanloo, A., \& Guillaume, R. O. (2019). (Re) Imagining an undergraduate integrating technology with teaching course. TechTrends, 63(1), 68-78.

Perry, E. H., \& Pilati, M. L. (2011). Online learning. New Directions for Teaching and Learning, 128, 95-104.

Pilgrim, M., Hornby, G., Everatt, J., \& Macfarlane, A. (2017). Evaluation of an innovative programme for training teachers of children with learning and behavioural difficulties in New Zealand. Educational Review, 69(3), 337-348.

Qayyum, A., \& Zawacki-Richter, O. (Eds.). (2018). Open and distance education in Australia, 
Europe and the Americas: National perspectives in a digital age. Springer Singapore. doi:10.1007/978-981-13-0298-5

Rehman, R., \& Fatima, S. S. (2021). An innovation in Flipped Class Room: A teaching model to facilitate synchronous and asynchronous learning during a pandemic. Pakistan Journal of Medical Sciences, 37(1), 131.

Reeves, T. C., \& Lin, L. (2020). The research we have is not the research we need. Educational Technology Research and Development, 68(4), 1991-2001.

Roser, M., \& Ortiz-Ospina, E. (2013). Primary and secondary education. Our World in Data.org. https://ourworldindata.org/primary-and-secondary-education

Samuel, J. C., Rosenzweig, A. H., McLean, M., \& Cintrón, R. (2019). One size fits none. In B. J. Beatty (Ed.), Hybrid flexible course design: Implementing student directed hybrid classes (Sec. 3.2). Edtechbooks.org. https://edtechbooks.org/hyflex/onesize_fits_none

Stacey, E., \& Visser, L. (2005). The history of distance education in Australia. Quarterly Review of Distance Education, 6(3), 253-259, 293.

Theelen, H., Willems, M. C., Van den Beemt, A., Conijn, R., \& den Brok, P. (2020). Virtual internships in blended environments to prepare preservice teachers for the professional teaching context. British Journal of Educational Technology, 51(1), 194-210.

Wiggins, G., \& McTighe, J. (2005). Understanding by design. (2nd ed.). Prentice Hall.

Wong, C. Y. C., Estudillo, A. G., \& Chapman, S. J. (2021). Blended learning in graduate teacher education programs: Understanding teacher candidates' perceptions and experiences. Currents in Teaching \& Learning, 12(2), 97-109.

Yoon, S. Y., \& Lee, C. H. (2012). The impact of explicit listening instruction on teacher preparation practices in blended learning. Language Learning, 15(4), 175-200.

Zainal, Z. (2007). Case study as a research method. Jurnal kemanusiaan, 5(1), 1-6.

\section{Authors}

Dr. Tonia Wilson is a Program Director at Weber State University. She has worked in Higher Education for over 14 years and is passionate about supporting students through innovation. Her research interests include reading and literacy, online learning, and community education programs.

Dr. Melina Alexander is a Professor at WSU with 30 years of experience in the field of education. She has been a professor in the department of teacher education at Weber State University for 16 years. Her areas of expertise include distance education, math education, secondary education, gender studies and justice and equity. In addition to her position in teacher education, Dr. Alexander is director of the Women and Gender Studies Program. 